\title{
Preliminary survey on tsetse flies and trypanosomosis at grazing fields and villages in and around the Nech Sar National Park, Southern Ethiopia
}

\author{
Girma Zeleke
}

CAHNET-ETHIOPIA, P.O. Box 21084-1000 (Private Bag), Addis Ababa Ethiopia

\begin{abstract}
Preliminary survey on tsetse flies and trypanosomosis were conducted between July and August 2007 at grazing fields and villages in and around the Nech Sar national park, with the ultimate intention of forwarding baseline information on the extent of the problem and possible control strategies. . Entomological (Tsetse flies) survey was conducted by deploying a total of 16 geo referenced NGU traps on the grazing fields of cattle. Parasitological (Trypanosomosis) survey and PCV (Packed Cell Volume) measurement were done on randomly selected 202 cattle, of the park neighboring villagers. Glossina pallidipes with mean apparent density of $11.46 \mathrm{ftd}$ (flies per trap per day) were found to be the only prevailing tsetse fly species in the study area. However, the mean apparent density of biting flies was found to be $4.54 \mathrm{ftd}$. Trypanosomosis with population mean estimated $17.33 \pm 5.30$ were seen to be a serious problem of cattle in the area. Trypanosoma congolense and $T$. vivax were the two dominant species encountered in the area. However statistically significant proportion of the cattle $(\mathrm{P}<0.005)$ were found infected with T. congolense. The overall mean PCV was $17.65 \pm 5.30 \%$. The mean PCV of the aparsitemic and parasitemic animals were found to be statistically significantly different $(\mathrm{P}<0.05)$. On the contrary, the number of cattle aparsitemic but anemic was also significant. These could be possibly due to infection by other recurrent parasites (such as haemonchosis, babesiosis and anaplasmosis), and nutritional deficiencies,. The present study disclosed that $G$. pallidipes to be the principal vector of trypanosomosis in the area. Thus, an urgent intervention on control mechanisms need to be adopted before the devastating impact of tsetse flies and trypanosomosis is aggravated to the extent of unbearable economic loss.
\end{abstract}

Keywords: Cattle, Trypanosomosis, Glossina pallidipes, PCV

\section{Introduction}

Tsetse flies are the cyclic vectors of trypanosomosis, a disease occurring mostly in rural areas affecting agro-pastoral activities in rural communities. 
The situation results in inadequate production of local food due to preventing optimal productive livestock -keeping and mixed farming (Feldmann et al., 2005). About 10 million $\mathrm{km}^{2}$ area of the 37 sub Saharan African countries are infested with tsetse flies (PATTEC, 2001). In Ethiopia about $200,000 \mathrm{~km}^{2}$ area in the western and south western parts of the countries infested with tsetse flies and thus African Animal Trypanosomosis (AAT) remains a serious problem (Temesgen Alemu et al., 2007)

In tsetse and trypanosomosis affected countries about 40-50 million animals are at risk of contracting the disease (Kamuanga, 2003; Shaw, 2004; Feldmann et al., 2005). Trypanosomosis is a chronic debilitating condition that reduces fertility (calving rate), weight gain, milk and meat off take by at least $50 \%$ (USD 2750 million per year) (Budd, 1999; Swallow, 1999; DFID, 2001; Shaw, 2004; Feldmann,2005). It can also result in death of affected animals (especially calves) if left untreated (Hursey and Slingenbergh, 1995; Feldmann, 2005). Moreover, trypanosomosis reduces the potential opportunities for livestock and crop production (mixed farming) through less drought animal power to cultivate land and less manure to fertile soils for enhanced crop production and also affects human settlement as people tend to avoid areas with tsetse flies (Shaw, 2004; Feldmann,2005).

Ethiopia has the highest total livestock unit and cattle population in Africa (AU/IBAR, 2003; Abayneh Dagne, 2005) and the livestock sub sector provides $30 \%$ of agricultural GDP, $14 \%$ of the foreign exchange and alone provides $16 \%$ of the total GDP (Abayneh Dagne, 2005). Meanwhile, the presence of tsetse flies and trypanosomosis, prevents optimal productive livestock keeping and mixed farming (Feldmann et al., 2005) resulting in inadequate exploitation of the sub sector. The current preliminary study was initiated and designed with the objective of offering baseline information on the prevalence of trypanosomosis, population density and species of tsetse flies and other mechanical vectors, to come up with alternative control options in alleviating the problem of tsetse and trypanosomosis.

\section{Materials and Methods}

\section{Study area}

The study was conducted at the grazing fields surrounding the Nech Sar National Park and five villages neighboring the National Park namely: Chcha, Harroropie, Shekeresha, Sulula and Tselkie. It is one of the National Parks, 
found in SNNPRS of Gamo Goffa Zone. The park is also known of its unique features of having forty (40) springs "Arba Minch" (BoFED, 2006).

\section{Study population}

Cattle of indigenous east African Zebu breed, grazing communally in and around the grassland zone of Nech Sar National Park were randomly selected.

\section{Tsetse survey}

The tsetse survey was conducted through deployment of geo referenced (using hand held Garmin 48xGPS) NGU traps at wood grass land and grass land vegetation coverage. The traps were deployed at altitudinal range of 11501228 meters above sea level. Traps were baited with acetone and cow urine, remained deployed for about 72 hours. After 72 hours trapped flies were identified, sexed, counted and recorded (IAEA, 2006).

\section{Trypanosome survey}

Parasitological and hematological techniques were employed. Accordingly, blood samples were obtained by bleeding marginal ear veins of cattle using a sterile lancet and drawing the blood into the heparinized capillary tube up to $3 / 4^{\text {th }}$ of the length and sealed with crystal seal. The collected blood was centrifuged for about 5 minutes with 12,000 rpm (revolutions per minute). After centrifugation the Packed Cell Volume (PCV) level was measured using hematocrit capillary reader .PCV below $25 \%$ was designated as anemic (Murry et al., 1977).

Blood smear was done via cutting the centrifuged blood containing capillary tube $1 \mathrm{~mm}$ above and below the buffy coat layer using a diamond tipped pencil. So as to include plasma and red cells in the blood smear. The blood then expressed on to the clean glass slide, mixed well and covered with a clean cover glass. Examination was done under 40x objective and 10x eye pierce magnification, using dark ground buffy coat technique (Murray et al., 1977)

\section{Statistical analysis}

One sample t-test was used to identify the marginal error of the means of trypanosomosis prevalence and means of PCV values for $95 \%$ CI. The significance of the difference in the mean PCV values of parasitemic and aparsitemic cattle were compared using two sample t-tests. Trypanosoma congolense and T. vivax 
difference in prevalence was analyzed using two proportion test for 95\% CI. Minitab version 13.1 statistical package was employed.

\section{Results}

\section{Tsetse survey}

The mean apparent density of tsetse flies in this preliminary survey was investigated as 11.46f/t/d (flies per trap per day). While the mean apparent density of mechanical vectors, tabanids was recorded to be $4.54 \mathrm{f} / \mathrm{t} / \mathrm{d}$. Species wise all of the 550 tsetse flies caught were Glossina pallidipes. Male and female G. pallidipes represented $37.81 \%$ and $62.18 \%$ of the total tsetse catch respectively.

Table 1: Glossina pallidipes and tabanids catch results, during the survey period at various altitudinal and vegetation ranges in and around the Nech Sar national Park

\begin{tabular}{|c|c|c|c|c|c|c|c|c|}
\hline \multirow[t]{2}{*}{ Trap Id } & \multirow{2}{*}{$\begin{array}{l}\text { Altitude } \\
\text { (masl) }\end{array}$} & \multirow[t]{2}{*}{ Vegetation } & \multicolumn{4}{|c|}{ G. pallidipes catch } & \multirow{2}{*}{$\begin{array}{l}\text { Tabanids } \\
\text { Catch }\end{array}$} & \multirow{2}{*}{$\begin{array}{c}\text { Tabanids } \\
\text { Apparent } \\
\text { Density } \\
\text { (f/t/d) }\end{array}$} \\
\hline & & & Male & Female & Total & $\begin{array}{c}\text { Apparent } \\
\text { Density } \\
\text { (f/t/d) }\end{array}$ & & \\
\hline NSP/M1/T01 & 1150 & WGL & 40 & 80 & 120 & 40.0 & 11 & 3.67 \\
\hline NSP/M1/T02 & 1154 & WGL & 1 & 2 & 3 & 1.0 & 3 & 1.0 \\
\hline NSP/M1/T03 & 1282 & WGL & 35 & 69 & 104 & 34.6 & 4 & 1.33 \\
\hline NSP/M1/T04 & 1298 & WGL & 3 & 14 & 17 & 5.66 & 2 & 0.66 \\
\hline NSP/M1/T05 & 1206 & WGL & 16 & 25 & 41 & 13.66 & 1 & 0.33 \\
\hline NSP/M1/T06 & 1164 & WGL & 61 & 70 & 131 & 43.66 & 2 & 0.66 \\
\hline NSP/M1/T07 & 1207 & WGL & 5 & 8 & 13 & 4.33 & 10 & 3.33 \\
\hline NSP/M1/T08 & 1199 & WGL & 7 & 11 & 18 & 6.0 & 9 & 3.0 \\
\hline NSP/M1/T09 & 1170 & WGL & 3 & 6 & 9 & 3.0 & 9 & 3.0 \\
\hline NSP/M1/T10 & 1174 & WGL & 9 & 19 & 28 & 9.33 & 14 & 4.67 \\
\hline NSP/M1/T11 & 1204 & GL & 11 & 7 & 18 & 6.0 & 38 & 12.67 \\
\hline NSP/M1/T12 & 1207 & WGL & 10 & 16 & 26 & 8.66 & 41 & 13.67 \\
\hline NSP/M1/T13 & 1222 & WGL & 3 & 7 & 10 & 3.33 & 25 & 8.33 \\
\hline NSP/M1/T14 & 1203 & WGL & 0 & 3 & 3 & 1.0 & 25 & 8.33 \\
\hline NSP/M1/T15 & 1244 & WGL & 3 & 4 & 7 & 2.33 & 20 & 6.67 \\
\hline NSP/M1/T16 & 1228 & WGL & 1 & 1 & 2 & 0.66 & 4 & 1.33 \\
\hline Total/Mean & & & 208 & 342 & 550 & 11.46 & 218 & 4.54 \\
\hline
\end{tabular}

NB; f/t/d-Flies per Day per Trap

WGL-Wood Grass Land, Type of vegetation coverage

GL-Grass Land, Type of vegetation coverage

masl-meter above sea level 
Trypanosoma survey

Parasitemia was detected in 35/202 cattle, which was $17.33 \%$ prevalence rate. ( $T$. congolense) was the prominent trypanosoma species encountered, that induced $94.29 \%$ of the total trypanosoma infection, where as $5.71 \%$ of the trypanosoma infection was caused by $T$. vivax . Highest trypanosoma infection rate was seen at the village by the name Shekeresha (29.17\%) and the least was seen at Sulula (11.63\%).

Table 2; Prevalence of cattle trypanosomosis in the four villages, in around the Nech Sar national park

\begin{tabular}{llccccc}
\hline No & $\begin{array}{l}\text { Sampling } \\
\text { Villages }\end{array}$ & $\begin{array}{c}\text { Sample } \\
\text { size }\end{array}$ & & \multicolumn{2}{c}{ Trypanosoma Encountered } & $\begin{array}{c}\text { Prevalence } \\
\text { (\%) }\end{array}$ \\
\cline { 3 - 6 } & & T. congolense & T. vivax & Total No Positive \\
Cattle & \\
\hline 1 & Chacha & 49 & 6 & 0 & 6 & 12.24 \\
2 & Shekeresha & 48 & 13 & 1 & 14 & 29.17 \\
3 & Sulula & 43 & 4 & 1 & 5 & 11.63 \\
4 & Tselkie & 62 & 10 & 0 & 10 & 16.13 \\
Total/ & 202 & 33 & 2 & 35 & 17.33 \\
Mean & & & & & \\
\hline
\end{tabular}

\section{PCV Measures}

The overall mean PCV value was found to be $17.65 \%$ with a range of maximum PCV $32 \%$ and minimum PCV $5.5 \%$. Significant proportion of parasitemic animals were anemic (97.14\%) indicating that anemia was being the important clinical indication of trypanosomes infection. Hundred and eighty eight (188) cattle had a PCV below $25 \%$, fourteen animals had $\geq 25 \%$. Out of cattle with the parasitemic status $97.14 \%$ found to be anemic and $92.22 \%$ of parasitemic were anemic.

Table 3: Packed Cell Volume of cattle examined for trypanosoma infection, at the four villages, in and around the Nech Sar National park

\begin{tabular}{llcccc}
\hline No & $\begin{array}{l}\text { Sampling } \\
\text { village }\end{array}$ & $\begin{array}{c}\text { Sample } \\
\text { size }\end{array}$ & $\begin{array}{c}\text { Mean } \\
\text { PCV(\%) }\end{array}$ & $\begin{array}{c}\text { No. Cattle } \\
\text { PCV } \geq \mathbf{2 5} \%\end{array}$ & $\begin{array}{c}\text { No. Cattle } \\
\text { PCV< 25 \% }\end{array}$ \\
\hline 1 & Chacha & 49 & 18.8 & 5 & 44 \\
2 & Shekeresha & 48 & 16.1 & 0 & 48 \\
3 & Sulula & 43 & 18.6 & 7 & 36 \\
4 & Tselkie & 62 & 16.7 & 2 & 60 \\
Total/Mean & 4 & 202 & 17.65 & 14 & 188 \\
\hline
\end{tabular}

Ethiop. Vet. J., 2011, 15 (1), 59-67 


\section{Discussion}

The present preliminary survey of tsetse flies depicted that G. pallidipes as the only species responsible for the cyclical transmission of trypanosomosis in the area. Baseline survey analysis report of block -1 STEP area made by Marck Vreysen (2000) has substantiated the presence of $G$. pallidipes as the only Glossina species in western and eastern parts of lake Abaya. Although $G$. f. fuscipes occurs in the deme basin a smaller valley in the north western part of the southern rift valley (Vreysen et al., 2000; Temesgen Alemu et al., 2007). This could possibly contribute for focusing on the eradication of $G$. pallidipes, through learning the past experience of other tsetse infested and cleared countries with similar species or one species of Glossina. For instance the successful eradication of G. austeni in Zanzibar, applying SIT (Sterile Insect Technique) was advantageous of a particular species and discrete zones or "island" infestation scenario (PATTEC, 2001). Since SIT involves mass production of target insect pest species (for the current case, G. pallidipes), sterilization and releasing into the field on a sustained basis and in sufficient numbers to achieve appropriate over flooding ratios (IAEA, 2006). The overall mean apparent density of $G$. pallidipes was found to be $11.46 \mathrm{ftd}$. The mean apparent density of mechanical vectors, tabanids was $4.54 \mathrm{ftd}$. Trypanosomosis with point prevalence of $17.33 \%$ and population mean estimated $17.33 \pm 5.30$ were seen to be a serious problem of cattle in the area. Trypanosoma congolense and T. vivax were the two trypanosoma spp encountered. However very significant proportion of the cattle $(\mathrm{P}<0.05)$ are infected of T. congolense. Thus, G. pallidipes remains the important cyclical vector of $T$. congolense in Arba Minch area. T. vivax can be seen in Africa where the tsetse belt is located hundreds of kilometers away. The parasite was also found to establish itself in western hemisphere, Bolivia, El Salvador, Central America, Cuba, Islands of Mauritius, where tsetse flies aren't present. T. vivax is reported to commonly exist in highlands of Ethiopia that is too cold for the tsetse survival (Uilenberg, 1998). Which is in accordance with the findings of this study, higher prevalence of $T$. congolense than $T$. vivax in tsetse free zones is considered as a result of mechanical transmitters (Roeder et al., 1984; Getachew Abebe and Yilma Jobre, 1996). These all evidences suggested the notion that, if any animal health problem posed on cattle due to trypanosomes is mainly of $G$. pallidipes as a vector. Significant proportion of parasitemic cattle (97.14\%) were seen to have anemia indicating that trypanosomosis is a wasting disease characterized by slow progressive loss of condition accompanied by increasing anemia (Uilenberg, 1998). The mean PCV of the aparsitemic (18.108 \pm 0.70$)$ and 
parasitemic $(15.457 \pm 1.37)$ animals were significantly different $(\mathrm{P}<0.05)$. In the contrary the number of cattle aparsitemic but anemic was also considerable. Infection by other recurrent diseases, some gastro intestinal parasites such as Haemonchus spp., hemoparasites like babesiosis and anaplasmosis and nutritional problems,(Radostits et al., 2006) ,might be the contributory factors for the paradoxical match of anemia with aparasitaemia. Thus, anemia is not the only and unequivocal indication of trypanosomosis. Tsetse flies in particular of G. pallidipes was found to be the sole vector of trypanosomosis and which in turn resulted in ill health and decreased production and productivity of cattle of the area. Control tactics against the flies (deployment of insecticide impregnated and odor baited cloth-panels, topical treatment of cattle, therapeutic and prophylactic administration of trypanocidal drugs and improvement of animal management and nutrition should be practiced. Investigation of all possible causes of anemia, trypanocidal efficacy test, fly infection rate and employment of molecular diagnostic techniques could be more helpful.

\section{Acknowledgment}

The author would like to thank African Parks P.L.C and STEP (Southern Tsetse Eradication Project) for all aspects of supports provided during the survey period.

\section{References}

Abebe, G and Jobre, Y., 1996. Trypanosomiasis; A threat to cattle production in Ethiopia. Rev.Med.Vet.147, 897-902.

Alemu, T., B. Kapitano, S. Mekonen, G. Aboset, M. Kiflom,B. Bancha, G.Woldeyes, K. Bekele and U. Feldmann, 2007. Area- wide control of tsetse and trypanosomiasis; Ethiopian experience in the southern rift valley, Pp.325-335. In: Vreysen, M.J.B ,A.S. Robinson and J. Hendrichs (eds.), Area wide control of insect pests, Springer, Dordrecht, the Netherlands

Anonymous, 2003. Baseline data of animal resources. In Pan African Animal Health year book, AU/IBAR.Pp.38-61

BoFED, 2006. Bureau of Finance and Economic Development Division of Statistics and Population Southern Nations, Nationalities and Peoples' Regional State.

Budd, L.T., 1999. DFID -funded tsetse and trypanosome research and development since 1980. volume 2- economic analysis. Department for International Development, UK 
Dagne, A. 2005. Strategic and innovative approaches to enhance livestock and livestock product export trade in Ethiopia, Pp.97-106. In: Proceedings of the EVA (Ethiopian Veterinary Association) on Strategic and innovative approach to enhance livestock export trade in Ethiopia: Animal health Markets and Institutions. The 19th Annual conference of the Ethiopian Veterinary Association (EVA) held in Addis Ababa, June 8-9, 2005, Ethiopia

DFID, Department for International Development. 2002. Trypanosomosis, tsetse and Africa. The year 2001 report.

Feldmann, U., V. A. Dyck. , R. C. Mattioli and J. Jannin. 2005. Potential impact of tsetse fly control involving the sterile insect technique. P701-723. In: Dyck, V. A. J.Hendrichs and A.S Robinson(eds.),Sterile Insect Techniques, principles and practice in Area-Wide Integrated Pest Management, Springer Dordrecht, the Netherlands.

Hursey, B.S., and J.Slingenbergh.1995.The tsetse fly and its effects on agriculture in Sub-Saharan Africa. World Animal Review 84/85(3-4): 67-73.

IAEA. 2006. Manual for conducting baseline tsetse surveys for Area-wide Integrated Pest Management Programmes (AW-IPM) version 1.International Atomic Energy Agency, Vienna, and Austria. Pp1-144.

Kamuanga, M. 2003. Socio-economic and cultural factors in the research and control of trypanosomiasis. PAAT Technical and Scientific Series 4. FAO, Rome, Italy.

Murray, M., Murray, P.K., Mc Intyre, W.I.M., 1977. An improved parasitological technique for the diagnosis of African trypanosomisis. Trans. R. Soc. trop. Med. Hyg. 71, 325-326.

PATTEC, 2001. Pan African Tsetse and Trypanosomosis Eradication Campaign, Plan of action, Organization of African unity, June 2001, Addis Ababa Ethiopia, Pp131

Radostits,O.M.,Gay,C.C.,Hinchcliff,K.W.,Constable,P.D.,2006.Veterinary Medicine, a text book of the diseases of cattle, horses, sheep, pigs and goats,10th edition, Saunders Elsevier, Edinburgh, London, New York, Oxford, Philadelphia, St Louis ,Sydney and Toronto.

Roeder, P.L., Scott, J.M., Pegram, R.G., 1984. Acute Trypanosoma vivax infection of Ethiopian cattle in the apparent absence of tsetse.Trop. Anim. Hlth Prod.,16, 141147 
Shaw, A. P. M. 2004. Economics of African Trypanosomiasis, Pp.369-402. In: I. Maudlin, P. H. Holmes and M. A. Miles (eds.). The Trypanosomosis. CABI Publishing, walling ford, U.K.

Swallow B.M.1999. Impact of Trypanosomosis on African Agriculture. PAAT Technical and Scientific Series 2. FAO, Rome, Italy.

Vreysen,M.J.B. 2000. Southern Rift Valley tsetse eradication programme.Analysis of the entomological baseline data collected between October 1998 and September 1999.Report to the IAEA, IAEA, Vienna, Austria.

Vreyesen, M. J. B. J. Gerardo -Abaya, and J.P.Cayol., 2007. Lessons from Area -wide integrated pest management (AW-IPM) programmes with an SIT component: an FAO/IAEA(Food and Agricultural Organization of the United Nations/International Atomic Energy Agency) perspective, Pp. 723-744. In Vreysen,M.J.B,A.S.Robinson and J. Hendrichs (eds.), Area wide control of insect pests, Springer, Dordrecht, the Netherlands. 